\title{
Analysis of Capacity and Level of Service (LoS) of Piet A. Tallo Street Kupang, Indonesia
}

\author{
Amy Wadu ${ }^{1 *}$, Onisius Loden ${ }^{1}$, Theresia Avila Bria ${ }^{1}$ \\ \{awd.ub15@gmail.com ${ }^{1}$, oniloden_2008@yahoo.co.id ${ }^{2}$, thessabria12@gmail.com ${ }^{3}$ \} \\ Civil Engineering Department, State Polytechnic of Kupang, Adisucipto Street, Penfui, Kupang, \\ Indonesia $^{1}$
}

\begin{abstract}
Traffic volume that exceeds the existing road capacity occurs on Jalan Piet A. Tallo during peak hours condition. Congestion often occurs in the mornings and evenings. In addition, there is a merging of the 4/2T road segment into $2 / 2 \mathrm{TT}$ which results in a buildup of traffic flow at that point so that some vehicles have to move outside the body of the road. This illustrates that the traffic flow and capacity of this road section are not proportional to the traffic volume at peak hours. Analysis of the capacity and performance of roads is based on the PKJI 2014. The results show that the performance of Jalan Piet A. Tallo Kupang in current conditions is heavily loaded because it exceeds the capacity of the road so that a queue of vehicles moves and stops alternately.
\end{abstract}

Keywords: capacity, level of service, PKJI, road, traffic, vehicle.

\section{Introduction}

Transportation plays a major role in the development of a region. Traffic performance is influenced by many factors such as road conditions, road shoulders and highways, drivers, width, side barriers or side activities, etc [1]. In recent years, traffic problems have become quite concrete problems in various cities. Low road capacity design especially in the construction of roads cannot keep up with the growth of traffic volume causing low levels of service and low capacity to accommodate the flow of traffic that crosses. This, of course, contributes to traffic congestion on urban roads [2]. The relationship between road capacity requirements and the growth of land use is clearly very influential with the growth rate of a $21.9 \%$ housing area and the growth rate of a work area of $24.8 \%$ resulting in an increase in traffic volume of $22-30 \%$ [3].

Kupang City is the capital of the East Nusa Tenggara Province which has been increasing in economy, trade and education from year to year. The rate of population growth in 20102017 was $2.97 \%$ with the rate of economic growth in 2017 was $6.83 \% \%$ [4]. Therefore it needs to be balanced with adequate infrastructure to meet the increasing needs of the citizens of Kupang City.

The number of vehicles in Kupang City which is increasing every year has the potential to cause serious problems in terms of traffic congestion in the coming years. The latest data on the growth of the total number of vehicles in the city of Kupang has increased by $7.99 \%$ each year with the largest percentage increase in the type of motorcycle vehicles of $8.22 \% \%$ [4]. An increase in the number of vehicles causes an increase in the movement of traffic flow that 
is not matched by an increase in infrastructure will cause congestion. One of the traffic jams in Kupang that often occurs during peak hours is on the Piet A. Tallo road.

The Piet A. Talo road section has a fairly high traffic volume plus this section is a meeting place for vehicles coming from the direction of Oesapa, Oebufu, Mayor's office complex and Penfui. In addition, this road also connects the largest college in NTT and the Kupang Regency Government Center in Oelamasi with the downtown area of Kupang, which is home to most college students and employees of the Kupang district government. The high volume of traffic passing on the road occurs during rush hour in the mornings, afternoons and evenings often with quite severe congestions on this section.

The increasing volume of vehicles that ride on this road and the existence of the $4 / 2 \mathrm{~T}$ unification to 2/2TT from STA $00+135.60$ to STA $00+530.62$ cause delays that result in congestion during peak hours. This results in the level of service for road users needing attention especially for the smooth flow of traffic [5]. The level of service (LOS) is a qualitative measure used to indicate traffic conditions in terms of speed, travel time, freedom to maneuver, comfort, traffic disruption, safety etc. The more ratios is, the greater the congestion will be. A value of 1.0 indicates heavy traffic. LOS which is suitable for various scenarios are presented to deal with existing traffic problems [6]. Based on the foregoing situation, this study will examine the capacity and level of service of the Piet A. Tallo road section.

\section{Research Methods}

\subsection{Research Stages}

The stages of the study began with initial observations, data collection, data processing and analysis, up to conclusions and suggestions. This research started from identifying the problems that occured after making direct observations in the study area. It was carried out to determine the problems occured in the study area. The study area and the scope of the problem to be discussed was also limited. The analysis phase was a follow-up after the data processing had been completed. The purpose of this stage was to understand and to analyze the results of data processing in depth. Analysis was carried out based on the Indonesian Road Capacity Guidelines 2014 (PKJ). The level of service was poor or did not meet the standards if DJ $\geq$ 0.75 [7].

\subsection{Data Collection}

Geometric data collection by manual method was carried out directly at the survey location by measuring the width of the road, the width of the sidewalk, and other data about road sections related to this study using a meter.

The traffic volume survey conducted in this study was a classified volume survey using the manual traffic count method based on Pd. T-19-2004-B from the Department of Settlements and Infrastructure. Data recording was done by filling the survey forms in accordance with the classification of vehicles that had been previously determined. The survey was conducted in 14 hours, from 06.00 to 20.00 on Monday, because Monday is a working day with the highest level of vehicles movement on the Piet A. Tallo road section.

The side friction survey was conducted with the intention of obtaining side friction data useful for calculating the capacity of a road section. The survey took 14 hours on the 
frequency of pedestrian events, vehicles stopped, vehicles going in and out of the side of the road, and vehicles slowing down at each section of the road.

The stages of the study began with initial observations, data collection, data processing and analysis, until the conclusions and the suggestions. Problem identification was carried out after making direct observations in the study area. This stage was implemented to determine the problems that occured in the study area. At this stage, the study area and the scope of the problem to be discussed were also limited. The analysis phase was a follow-up after the data processing had been completed. The purpose of this stage was to understand and to analyze the results of data processing in depth. Analysis was carried out based on the Indonesian Road Capacity Guidelines 2014 (PKJI). The level of service was poor or did not meet the standards if $\mathrm{DJ} \geq 0.75$ [7].

\section{Results and Discussion}

\subsection{Geometric of Road}

Road conditions can consist of various geometric parameters that describe the road, such as the type of facility, track width, shoulder width, and horizontal and vertical alignment. Horizontal alignment, especially the characteristics of horizontal curves, can have a large impact on the traffic flow [8]. Figure 1 shows the geometric of road conditions of Piet A. Tallo Street. It is divided into 2 segments, the first segment is shown on Figure 1 (a) which is a 2-way road segment with 4 divided lanes with the width of $3.5 \mathrm{~m}$ and hereinafter referred to as 4 / 2T. Figure 1 (b) is a 2-way road segment with 2 undivided directions with each lane and a width of $3.5 \mathrm{~m}$, hereinafter referred to as $2 / 2 \mathrm{TT}$. Increasing volume of vehicles that pass through this road and the existence of $4 / 2 \mathrm{~T}$ unification to $2 / 2 \mathrm{TT}$ from STA $00+135.60$ to STA $00+530.62$ caused delays that result in congestion during peak hours. In the study [9] we found out that the most influential variable on road capacity was lane width, followed by median width.

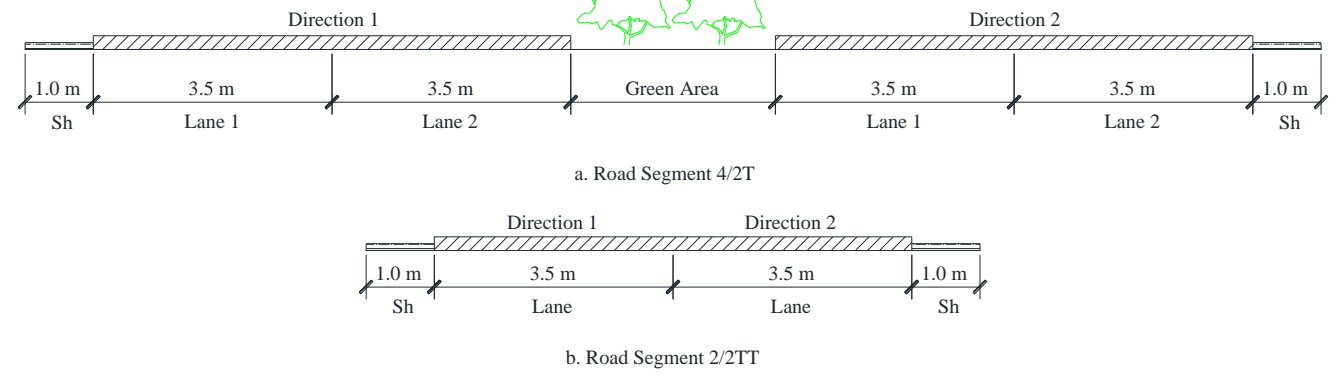

Fig. 1. Cross Section of Road

\subsection{Volume of Traffic}

The series activities on data management include calculations to determine the current condition of the road segments by referring to the calculation procedures established by the Indonesian Road Capacity Guidelines (PKJI 2014). The calculation procedure contains stepby-step instructions undertaken for the analysis of roads with the help of forms JK-1, JK-2 and JK-3. From the survey results of traffic volume data collection, the data is then processed and 
shown in the figures. The highest current is determined in the segment of the road with units of vehicles per hour (vehicle / hour). The volume of traffic on a total current road segment whose unit is still an hourly vehicle must be changed to an hourly light vehicles unit (skr / hr). To change the traffic volume unit from an hourly vehicle (vehicle / hour) to a car unit hourly passengers (skr/hr), it is firstly multiplied by the equivalent number of light vehicles (ekr) set by the 2014 Indonesian Road Capacity Guide (PKJI-2014)

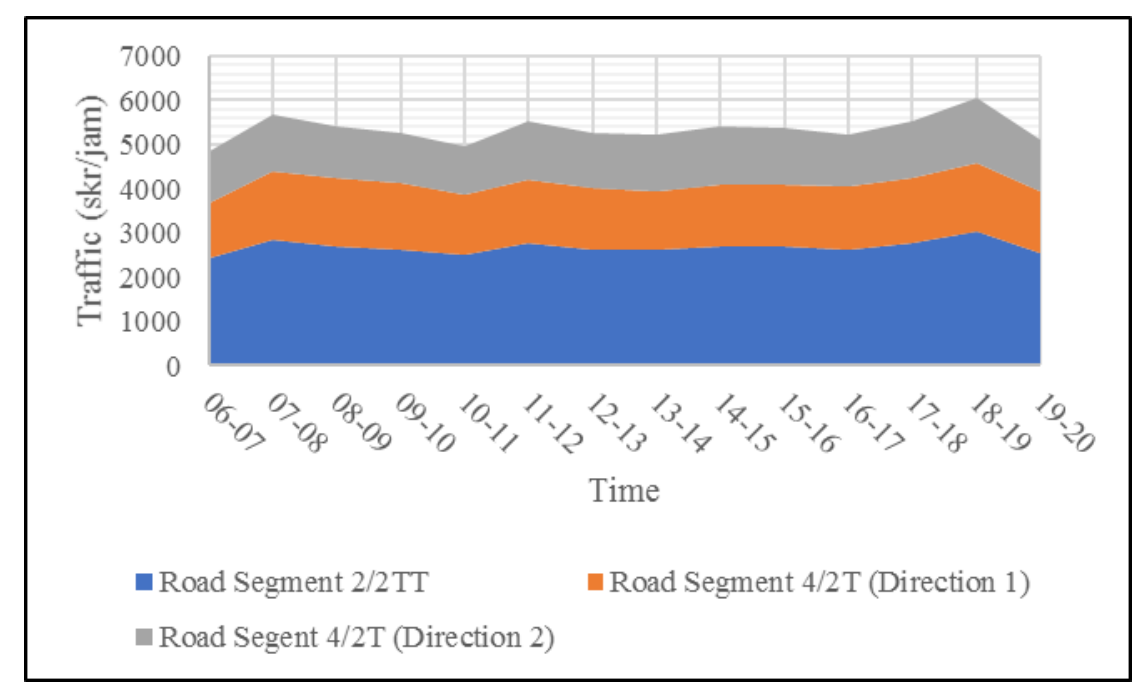

Fig. 2. Traffic Volume

Figure 2 shows the data during the peak hours flow on the Piet A. Tallo road from 18:00 to 19.00 ie $1541 \mathrm{skr} /$ hour road segment $4 / 2 \mathrm{~T}$ direction 1 , and $1492 \mathrm{skr} /$ hour for $4 / 2 \mathrm{~T}$ direction 2. This peak hours occurs due to the activity of the community going home from either work namely employees and or students from universities and schools . On top of that, in this section of the area, there is a number of culinary places that people come for food or drinks which contributes to traffic congestions..

\subsection{Capacity of Road}

The capacity of the road section obtained from the calculation of the capacity of the road segment is the actual capacity of the road. Road capacity is a necessary requirement here because there is a development of land use that encourages generation or pull of movement. At the same time it encourages contribution to traffic growth and can improve congestion [3].

The actual capacity of the road is determined through the results of calculations using an empirical formula based on the PKJI. After the calculation using the formula above, the results obtained are the actual capacity of Jalan Piet A. Tallo as in Figure 3. The basic capacity obtained is determined based on the number of lanes in the study area. The location of the study of Piet A Tallo Road has 2 segment characteristics, the first segment is a one-way street with 4 divided lanes $(4 / 2 \mathrm{~T})$. The second segment is a 2 -way road with 2 undivided lanes (2/2TT), a 2-lane 2-way road divided with the basic capacity of $(\mathrm{C} 0=1650 \mathrm{skr} /$ hour total one-way and $2900 \mathrm{skr} /$ hour for 2-way total roads). 


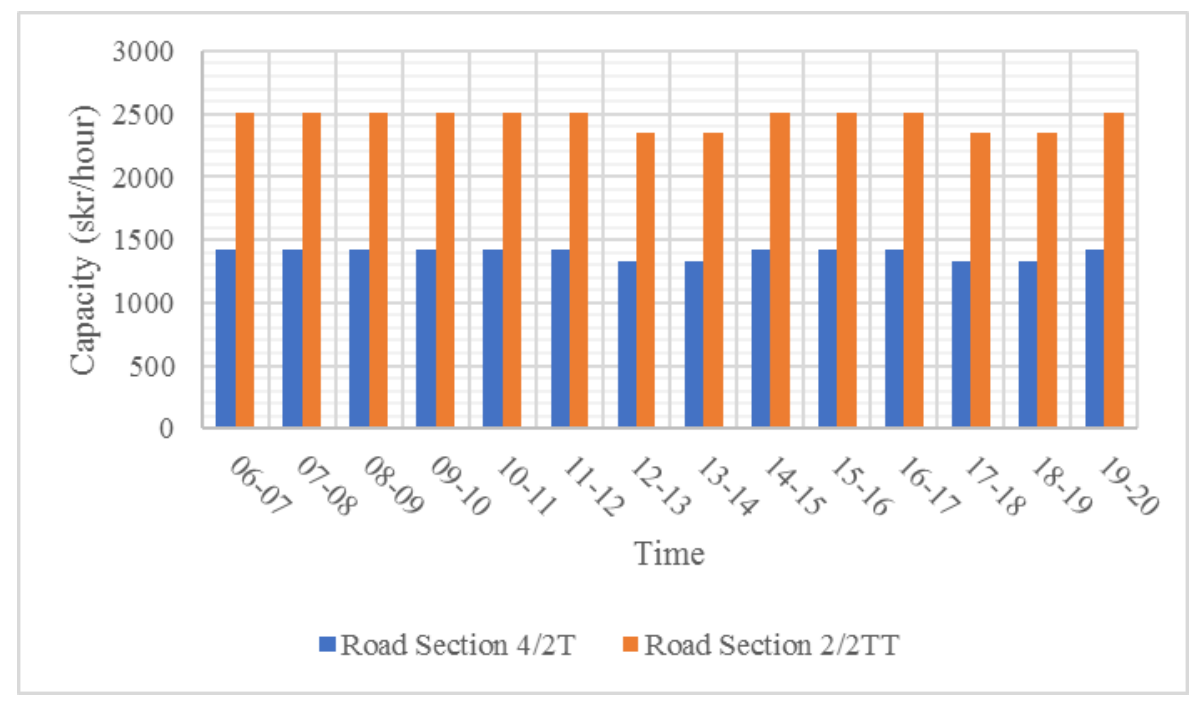

Fig. 3. Road Capacity

In Figure 3, the minimum reduction in the capacity of the Piet A. Tallo road section occurs from 18:00 to 19:00 hours with $1335 \mathrm{skr} / \mathrm{hr}$ on the segment of 2/1T direction 1, 1427 $\mathrm{skr} / \mathrm{hr}$ on the segment of $4 / 2 \mathrm{~T}$ direction 2 , and $2346 \mathrm{skr} / \mathrm{hr}$ on the segment of 2/2TT. The capacity decreases from 18:00 to 19:00 due to the increase inside friction that occurs. And it mostly happens due to increased activity in the commercial areas around the Piet A. Tallo road section from 18:00 to 19:00.

\subsection{Level of Service (LoS)}

The performance of a road is indicated by the level of road service (LoS) [10]. In this approach, the LOS assessment is based on the type of facility which compares the volume and capacity of the road sections. The best level of service is provided by facilities with volume / capacity values. [11]. The maximum hourly volume rate at which vehicles can cross certain points under conditions applies at a reasonable level of service [6]. During the design of the road, the main thing to be kept in mind is the need for smooth vehicle movement, the volume of services related to Level of Service (LOS) C.At this level, according to the PKJI 2014 provisions the traffic volume will be 0.75 times the capacity. Based on the analysis conducted based on the PKJI 2014, it was found that the performance data of the Piet A. Tallo Road section for the largest volume, on busy working days, ie Monday is shown on Figure 4. 


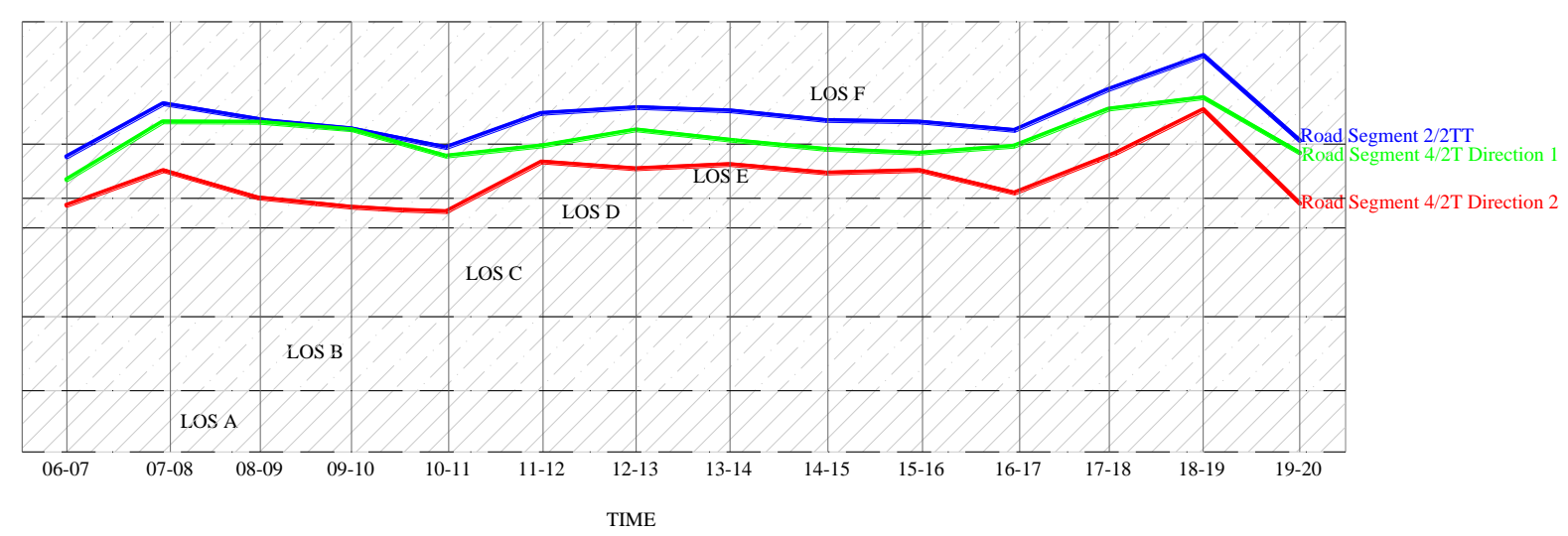

Fig. 4. Level of Service

See Figure 4, The overall results of the analysis of the performance of the existing road sections indicates that the performance of the Piet A. Tallo Road section is less than ideal condition required by the PKJI 2014 or it can be said to be in poor condition. The service level at peak hours (18.00-19.00) on the 4/2T segment of the road is 1.15 for direction 1 and 1.12 and it becomes worse when changing to the $2 / 2 \mathrm{TT}$ segment with a service level of 1.29 . This means that in this condition the traffic flow is forced, unstable, and there is a queue of vehicles moving and stopping alternately, increasing several vehicles resulting in total traffic jams. Based on the results of direct observations and field observations, for some busy time especially on Monday, there was a significant traffic jam. The conflict can be seen from the queue of vehicles in the road segment. Analysis of this condition is congestion or queuing in addition was mainly caused by the density of vehicles, and also by delays. On top of that side obstacles are also caused both people crossing and vehicles moving in and out of the Kupang Poltekes campus complex plus parking vehicles in commercial areas around the body of the street. But generally after passing the point of conflict the flow returns to normal.

\section{Conclusion}

The conclusions obtained based on the results of observations and analysis on Piet A. Talo streetare as follows:

1. The peak hour volume on the Piet A. Tallo Kupang Road section in the existing condition occurs from 18:00 to 19:00 with $1541 \mathrm{skr} /$ hour in the 4/2T segment of direction 1 and $1492 \mathrm{skr} /$ hour in the 4/2T segment of direction 2.

2. The capacity of the Piet A. Tallo Kupang road segment at peak hours is $1335 \mathrm{skr} / \mathrm{hr}$ for the 4/2T segment of direction $1,1427 \mathrm{skr} / \mathrm{hr}$ for the 4/2T segment of direction 2 , and $2346 \mathrm{skr} / \mathrm{hr}$ for the 2/2TT segment

3. The performance of the Piet A. Tallo Road in the existing condition based on the degree of saturation has exceeded the standard limit of 1.15 for the $4 / 2 \mathrm{~T}$ segment of direction 1 , and 1.12 for the $4 / 2 \mathrm{~T}$ segment of direction 2 which became 1.29 and became a segment 2/2TT which exceeded the standard limits set in the Indonesian Road Capacity Guidelines (PKJI) of only 0.75 . 


\section{References}

[1] A. M. Rao, S. Velmurugan a K. M. Lakshmi, „Evaluation of Influence of Roadside Frictions on the Capacity of Roads in Delhi, India,“ rev. Transportation Research Procedia, Shanghai, 2017.

[2] X.-p. WU a X.-h. DU, „Research and Practice on Equilibrium Theory of Road Capacity,“ rev. 13th COTA International Conference of Transportation Professionals (CICTP 2013) , Shenzhen, 2013.

[3] A. Tennøy, A. Tønnesen a F. Gundersen, „Effects of urban road capacity expansion Experiences from two,“ Transportation Research Part D, pp. 90-106, 2019.

[4] Badan Pusat Statistik, „Kota Kupang Dalam Angka 2018,“ BPS Kota Kupang, 2018, 2018.

[5] A. M. Hadut, „Analisis Tingkat Pelayanan Ruas Jalan (Studi Kasus Jalan RW Monginsidi-Kota Kupang, NTT),“'UAJY, Yogyakarta, 2017.

[6] R. Gajjar a D. Mohandas, „Critical Assessment of Road Capacities on Urban Roads - A Mumbai Case-Study," rev. 11th Transportation Planning and Implementation Methodologies for Developing Countries, TPMDC 2014, Mumbai, 2016.

[7] Pusat Penelitian dan Pengembangan Jalan dan Jembatan, Panduan Kapasitas Jalan Indonesia, Jakarta: Kementerian Pekerjaan Umum Indonesia, 2014.

[8] H. . I. Hassan a A.-W. T. Ali, „Effect of Highway Geometric Characteristics on Capacity Loss,“ Journal Of Transportation Systems Engineering And Information Technology, pp. 65-75, 2012.

[9] A. M. Semeida , „New Models To Evaluate The Level Of Service And Capacity For Rural Multi-Lane Highways In Egypt,“ Alexandria Engineering Journal, pp. 455-466, 2013.

[10] A. Wadu, R. Kusumawardhani a I. Suherminingsih, „Manajemen Lalu Lintas Di Jalan Lingkar Kampus Universitas Brawijaya,“Juteks - Jurnal Teknik Sipil, pp. 266-272, 2018.

[11] H. Sulistio, „Transportasi dan Tata Guna Lahan,“ Teknik Sipil Universitas Brawijaya, Malang, 2008. 